\title{
Effects of Exogenous Enzymatic Treatment During Processing on the Sensory Quality of Summer Tieguanyin Oolong Tea from the Chinese Anxi County
}

\author{
Xue-Bo Zhang ${ }^{1,2}$ and Xian-Feng Du ${ }^{1 *}$ \\ ${ }^{1}$ State Key Laboratory of Tea Biology and Utilization, Anhui Agricultural University, Hefei, \\ Anhui, 230036, PR China \\ ${ }^{2}$ National Tea Quality Supervision and Inspection Center (Fujian), Anxi, Fujian, 362400, PR China \\ Received: March 13, 2014 \\ Accepted: March 18, 2015
}

\begin{abstract}
Summary
In order to attenuate the bitter taste and improve the aroma of the summer tieguanyin oolong tea from the Chinese Anxi county, the effects of processing treatment with exogenous laccase and $\alpha$-galactosidase on tea sensory quality and related compounds were investigated. The solutions of laccase and/or $\alpha$-galactosidase were sprayed on the tea leaves before the first drying process. The sensory evaluation results showed that the sensory quality of the tea was significantly enhanced with the enzymatic treatment. The combined application of laccase at 8.25 and $\alpha$-galactosidase at $22 \mathrm{U}$ per $\mathrm{kg}$ of fresh tea shoots achieved the most satisfying sensory quality. Further analysis of flavour-related constituents was carried out by HPLC and GC-MS. The HPLC analysis showed that the contents of catechins and total polyphenols were reduced, compared to the untreated group, by 11.9 and $13.3 \%$ respectively, and the total soluble sugars and water extract content were increased by 19.4 and $6.6 \%$ respectively, after the treatment with both enzymes. The decrease of catechins and total polyphenols reduced the bitterness and astringency of the summer tea, while the increase of total soluble sugars and water extract content improved the sweetness and mellow taste. The aromatic compound data from GC-MS showed that the total essential oil content in these tea samples co-treated with laccase and $\alpha$-galactosidase increased significantly, in which aldehydes, alcohols, esters and alkenes increased by 23.28, $37.05,20.10$ and $38.99 \%$, respectively. Our data suggest that the exogenous enzymatic treatment can enhance the summer oolong tea quality, especially its taste and aroma.
\end{abstract}

Key words: summer tieguanyin oolong tea, exogenous enzymatic treatment, laccase, $\alpha$-galactosidase, sensory quality

\section{Introduction}

Tea, a popular healthy beverage consumed around the world, is classified into six types: green tea, yellow tea, dark tea (including brick tea and pu-erh tea), white tea, oolong tea and black tea based on the degree of fermentation (oxidation) during processing (1). These types of tea have different quality characteristics including colour, aroma, taste and appearance. Many studies have shown the positive effects of green and black tea on oxidative and inflammatory stress, insulin resistance and lipid metabolism (2). Oolong tea has proven its effects on antioxidation, lipid reduction and anti-obesity (3).

The fresh tea leaves are rich in catechins (flavan-3-ols), caffeine and theanine ( $N$-ethyl- $\gamma$-L-glutamine), which contribute to the main health-promoting functions and sensory quality of tea. Moreover, there are abundant gly- 
cosides with monoterpene alcohols and aryl alcohols like aglycone, which having been hydrolysed by endogenous glucosidase release the aglycone during processing. These compounds have floral or fruity smell and dominate the formation of tea aroma (4). During the processing period of oolong tea, fresh tea leaves are harvested and undergo the basic steps of being withered, bruised (shaken), partially fermented, fixed, rolled and dried. Oxidation is limited only to the leaf edges through shaking, known as 'semi-fermentation'. Tieguanyin tea, a kind of oolong tea that originates from Anxi county (Fujian province, PR China), is one of the top ten famous teas in China and is processed from Tieguanyin cultivar. Besides natural conditions and good agricultural practices of tea plantations, the season of tea production plays an important role in quality. According to the harvest time, tieguanyin tea is classified into spring, summer and autumn tea. It has been found that summer tea has higher output than spring and autumn tea, but generally has lower quality (5), the difference being that summer tea has fewer soluble sugars and more polyphenols and caffeine, undesirable bitter and astringent taste with lower quality aroma. Given the situation, it is necessary and justifiable to find ways to improve the sensory quality of summer tieguanyin tea.

To optimize the unique quality of tea, endogenous enzymes like polyphenol oxidase and glucosidase in tea shoots should be well controlled. However, this is restricted by the quality of fresh leaves and the production process. Many attempts such as changing the processing conditions have been made to improve the quality of summer tea $(6,7)$. In addition, it has been reported that the quality of tea and related tea products has been improved by introducing some exogenous enzymes such as polyphenol oxidase, peroxidase, tannase, cellulase, pectinase, protease and $\beta$-glucosidase into tea processing since 1990s. For example, Murugesan et al. (8) did screening experiments with a series of exogenous enzymes and found that the purified cellulase combined with laccase from Trametes versicolor in the ratio of 3:2 (by volume) was the most effective in enhancing the quality of black tea. In 2013, Kumar et al. (9) reviewed various major enzymatic methods applied in the ready-to-drink black tea production and discussed the advantages and limitations of these methods. As far as green tea is concerned, $\beta$-glucosidase could significantly enhance the aromatic constituents in green tea liquor (10), papain and cellulase could reduce its bitterness (11), and the proteolytic enzyme derived from Aspergillus oryzae could hydrolyse proteins in green tea residues (12). Besides, peroxidase, cellulase and Flavourzyme ${ }^{\circledR}$ were employed by Li and Liu in 2008 (13) in the processing of pu-erh tea to improve its quality. Above all, exogenous enzyme treatment can achieve the purpose of improving tea quality by changing the contents of some constituents in the tea.

Laccase is one of the copper-containing polyphenol oxidases ( $p$-diphenol oxidase, EC 1.10.3.2), which was first found in sumac juice in 1883 (14) and is widely present in fungi and bacteria $(15,16)$. Its substrates include, among others, polyphenols, methoxy-substituted phenols and diamines. Laccase is able to transform phenols by self-coupling or cross-coupling with polymeric products. Canfora et al. (17) proved that laccase was effective in the transformation of simple and complex phenolic mixtures. Luo et al. (18) studied the effect of the kinetics of biocatalytic activity of laccase during oxidation of phenolic compounds and demonstrated that laccase-catalysed oxidation of phenolic compounds was more effective than that of epicatechin and catechol. Yue (19) performed the study on synthesising theaflavins by using laccase. Therefore, laccase has been widely used in food industry (20-22), such as for juice clarification, beer processing stability and food sensory quality improvement. It can deoxygenate oil, remove bitterness and other unpleasant tastes of cacao, reduce the bitterness of olives, improve the colour and enhance the quality of black tea (8).

The $\alpha$-galactosidase (EC 3.2.1.22), originally from the yeast fermentation liquid, exists in many animals, plants and microorganisms. It can specifically hydrolyse $\alpha$-galactosidase bond and has been widely applied in food, feed and medical industry (23-25). In food processing, $\alpha$-galactosidase is used mostly to remove 'flatus-producing factor' in soya bean, thereby reducing soya bean oligosaccharides and making it easily digestible (26-28).

To the best of our knowledge, so far there have been no reports on the effects of processing treatment of exogenous laccase and $\alpha$-galactosidase on the sensory quality of summer tieguanyin tea from the Anxi county in China. In order to improve the fragrance quality of the tea by reducing bitterness and astringency, we investigated the effects of laccase and $\alpha$-galactosidase on the final tea quality. The main constituents related to its taste and aroma were also analysed.

\section{Materials and Methods}

\section{Materials}

Summer fresh tea shoots (Camellia sinensis cv. Tieguanyin), consisting of dormant bud and three or four adjacent leaves, were hand-plucked in July 2011 from the fields of the Xianghua Tea Factory, Anxi Tie Guan Yin Group, Anxi, Fujian province, PR China.

Laccase $5000 \mathrm{U} / \mathrm{g}$ and $\alpha$-galactosidase $5000 \mathrm{U} / \mathrm{g}$ were purchased from Aidun Biology Engineering Company (Jiangsu, PR China). Glucose, catechin (including epigallocatechin, epicatechin, epigallocatechin gallate and epicatechin gallate), caffeine, theanine and gallic acid standards were purchased from Sigma-Aldrich (Shanghai, PR China). Other reagents were of HPLC or analytical grade. Ultrapure Milli-Q Direct 8 water was produced by Merck Millipore (Billerica, MA, USA).

\section{Enzymatic treatment}

The basic manufacturing process for summer fresh tea shoots according to Chinese National Standard GB/T 19598-2006 (29) includes the following steps: plucking $\rightarrow$ withering and cooling $\rightarrow$ bruising and rolling $\rightarrow$ fixation $\rightarrow$ twisting and wrapping $\rightarrow$ first drying $\rightarrow$ full drying. For enzymatic treatment, $10 \mathrm{~kg}$ of half-dried tea were sprayed with $220 \mathrm{~mL}$ of aqueous solution containing enzymes prior to full drying, rolled for $2 \mathrm{~min}$ and left for $10 \mathrm{~min}$ in tea baking box, and then dried fully at $70-80^{\circ} \mathrm{C}$. 
As shown in Table 1, the sample not treated with the enzymes was labelled $\mathrm{CK}$, the groups treated with laccase (0.05, 0.1 and $0.2 \mathrm{~g} / \mathrm{L}) \mathrm{A} 1, \mathrm{~A} 2$ and A3 respectively, the groups treated with $\alpha$-galactosidase $(0.1,0.2$ and $0.4 \mathrm{~g} / \mathrm{L})$ B1, B2 and B3, and the groups treated with both laccase and $\alpha$-galactosidase (in g/L: laccase $0.075+\alpha$-galactosidase 0.1 and laccase $0.075+\alpha$-galactosidase 0.2$) \mathrm{C}$ and $\mathrm{D}$ respectively. Three parallel experiments were done at each concentration.

Table 1. Concentrations of enzymes used for the treatment of different summer tieguanyin tea samples

\begin{tabular}{cc}
\hline Sample & $\gamma($ enzyme $) /(\mathrm{g} / \mathrm{L})$ \\
\hline CK & Not treated enzymatically \\
A1 & Laccase 0.05 \\
A2 & Laccase 0.1 \\
A3 & Laccase 0.2 \\
B1 & $\alpha$-galactosidase 0.1 \\
B2 & $\alpha$-galactosidase 0.2 \\
B3 & $\alpha$-galactosidase 0.4 \\
C & Laccase $0.075+\alpha$-galactosidase 0.1 \\
D & Laccase $0.075+\alpha$-galactosidase 0.2 \\
\hline
\end{tabular}

\section{Sensory evaluation}

The tea samples were examined and scored independently according to Chinese National Standard GB/T 23776-2009 (30) by a tea tasting panel consisting of six experts from the Department of Tea Science, Anhui Agricultural University, Hefei, PR China. The tea tasters firstly evaluated the appearance of the dry leaves, including colour, size and twist. A mass of $5.0 \mathrm{~g}$ of tea samples was infused three times (for 2, 3 and $5 \mathrm{~min}$ ) in a $110-\mathrm{mL}$ tea tasting porcelain cup with $110 \mathrm{~mL}$ of freshly boiled water, and then the infusions were poured three more times into $110-\mathrm{mL}$ tea tasting porcelain bowls for quality assessment. Finally, the tea tasters assessed the aroma, colour and taste of the infusion based predominantly on the infusion time of $3 \mathrm{~min}$. The grading system was based on the maximum score of 100 for each quality attribute (aroma and taste).

\section{Determination of total polyphenolic content}

The total polyphenols, caffeine, catechins, free amino acids, tea polysaccharides and water extracts of the tea samples were examined by National Tea Quality Supervision and Inspection Center, Fujian, PR China. The total polyphenolic content (TPC) was determined by spectrophotometry (722S, Shanghai Analytical Instrument Company, Shanghai, PR China), using gallic acid as the standard, according to the method described in the International Standard ISO 14502-1:2005 (31). Briefly, $1.0 \mathrm{~mL}$ of the diluted samples was transferred in duplicate to separate tubes containing $5.0 \mathrm{~mL}$ of a 1:10 dilution of Folin-Ciocalteu reagent in water. Then, $4.0 \mathrm{~mL}$ of a sodium carbonate solution $(7.5 \%$, by mass per volume) were added. The tubes were then allowed to stand at room temperature for $60 \mathrm{~min}$ before absorbance was measured at $765 \mathrm{~nm}$ against water. The TPC was expressed as gallic acid equivalents
(GAE) in $\mathrm{g}$ per $100 \mathrm{~g}$ of material. The concentration of polyphenols in the samples was derived from a standard curve of gallic acid ranging from 10 to $60 \mu \mathrm{g} / \mathrm{mL}$ (Pearson's correlation coefficient: $\mathrm{R}^{2}=0.998$ ).

\section{Determination of caffeine and catechins}

Caffeine and catechins were quantified by Chinese National Standard GB/T 8312-2013 (32) and International Standard ISO 14502-2:2005, respectively (33). Caffeine and catechins were analysed by a HPLC system (2695/ 2996, PDA detector, Waters, Milford, MA, USA) equipped with a reversed phase Waters $C_{18}$ column $(5 \mu \mathrm{m}, 250 \mathrm{~mm} \times$ $4.6 \mathrm{~mm}$ i.d.) at $35{ }^{\circ} \mathrm{C}$ and $278 \mathrm{~nm}$. Concentrations of caffeine and catechins were quantified by their peak areas against those of standards prepared from authentic compounds.

\section{Determination of water extract, tea polysaccharides and free amino acids}

Water extract was determined according to Chinese National Standard GB/T 8305-2013 (34). Briefly, a volume of $50 \mathrm{~mL}$ of tea extract prepared as described above was evaporated in a dish on boiling water bath to partially dry, and further dried in an oven at $103{ }^{\circ} \mathrm{C}$ to complete dryness and then weighed after cooling down to room temperature in a silica gel desiccator.

Tea polysaccharides were determined by an anthrone-sulphuric acid method described by Wang et al. (35). A volume of $4 \mathrm{~mL}$ of $0.033 \%$ anthrone in concentrated sulphuric acid was added to $1 \mathrm{~mL}$ of tea polysaccharide solution and heated for $7 \mathrm{~min}$ at $100{ }^{\circ} \mathrm{C}$. The absorbance was measured at $620 \mathrm{~nm}$ after cooling for $30 \mathrm{~min}$, and glucose was used as the standard. The result was expressed in $\mathrm{g}$ of glucose per $100 \mathrm{~g}$ of material and derived from a standard curve of glucose ranging from 0.025 to $0.2 \mathrm{mg} / \mathrm{mL}$ (Pearson's correlation coefficient: $\mathrm{R}^{2}=0.999$ ).

The content of free amino acids was determined spectrophotometrically at $570 \mathrm{~nm}$ with ninhydrin colourimetry, using theanine as standard, according to Chinese National Standard GB/T 8314-2013 (36). It was expressed in $\mathrm{g}$ of theanine per $100 \mathrm{~g}$ of material and derived from a standard curve of theanine ranging from 0.004 to $0.012 \mathrm{mg} /$ $\mathrm{mL}$ (Pearson's correlation coefficient: $\mathrm{R}^{2}=0.985$ ).

\section{Determination of aromatic compounds}

The aromatic compounds were analysed and determined by brewed extraction method reported by Kawakami et al. (37). In brief, a simultaneous steam distillation and extraction apparatus was used to extract volatile compounds with ethyl ether as the extraction solvent, and then the extracts were concentrated. Finally, the concentrates were determined by gas chromatography-mass spectrometry (GC-MS, QP2010S, Shimadzu, Kyoto, Japan).

Aromatic compounds were extracted as follows: $30 \mathrm{~g}$ of tea sample were mixed with $500 \mathrm{~mL}$ of deionized water in a 1-litre flask, and $1 \mathrm{~mL}$ of ethyl decanoate solution (50 $\mu \mathrm{g} / \mathrm{mL}$ in ethyl ether) was added as an internal standard for GC-MS quantitative analysis. Then, the volatile constituents were extracted applying simultaneous distillation and extraction method using a modified Likens- 
-Nickerson apparatus. A volume of $30 \mathrm{~mL}$ of redistilled ethyl ether was used as the extraction solvent, and the extraction was continued for $1 \mathrm{~h}$ after the sample began boiling in the flask. The ethyl ether phase was then transferred into a $50-\mathrm{mL}$ glass tube and dehydrated with $5 \mathrm{~g}$ of anhydrous sodium sulphate overnight. The dehydrated ethyl ether phase was then concentrated to $1 \mathrm{~mL}$. The concentrate was used for GC-MS analysis.

The flavour substances were analysed by GC-MS, with DB-5 chromatographic column ( $30 \mathrm{~m} \times 0.25 \mathrm{~mm} \times 0.25$ $\mu \mathrm{m}$ i.d.). The oven temperature was kept at $50{ }^{\circ} \mathrm{C}$ for 2 min, then raised to $60{ }^{\circ} \mathrm{C}$ at a rate of $1^{\circ} \mathrm{C}$ per min, maintained for $2 \mathrm{~min}$, then raised to $150{ }^{\circ} \mathrm{C}$ at a rate of $3{ }^{\circ} \mathrm{C}$ per min, and maintained for $5 \mathrm{~min}$, then raised to $250{ }^{\circ} \mathrm{C}$ at a rate of $10{ }^{\circ} \mathrm{C}$ per min and maintained for $7 \mathrm{~min}$. The injector temperature was $250{ }^{\circ} \mathrm{C}$. The temperature of the detector was $280^{\circ} \mathrm{C}$. Highly purified helium was used as carrier gas with a constant flow rate at $1.0 \mathrm{~mL} / \mathrm{min}$. The split ratio was $1: 10$ and the injection volume was $1 \mu \mathrm{L}$. Mass spectrometry was performed in electron ionization mode by scanning the mass spectra at $70 \mathrm{eV}$ in an $\mathrm{m} / \mathrm{z}$ range from 35 to 400 . The aroma constituents were identified by matching GC and MS data with those of authentic compounds and the literature. The relative amount of each compound was calculated by the ratio of the compound peak area to the internal standard (ethyl decanoate) peak area.

\section{Data analysis}

The experimental data about taste were shown as the average value \pm standard deviation $(N=3)$. Data were analysed using data processing system (DPS) for analysis of variance (ANOVA), with statistically significant difference at $\mathrm{p}<0.05$.

The aromatic constituents were identified by NIST 147 and NIST 27 libraries (38).

\section{Results and Discussion}

Tea taste and aroma are the most important indices to evaluate the sensory quality of oolong tea. Taste reflects the coordination effects of various water-soluble substances in tea infusion, which include soluble phenols, caffeine, amino acids, soluble sugars, etc. Sensory aroma character- istics of tea depend on the total amount of essential oil and the abundance of various aromatic compounds.

Summer tieguanyin tea has plain and thin but bitter and astringent taste and plain aroma. In order to improve the quality of summer tea, the exogenous enzymes laccase and $\alpha$-galactosidase were added to adjust the content of one or several taste and aromatic factors.

\section{Sensory evaluation results of tea samples}

The sensory evaluation results of the samples CK, A1, A2, A3, B1, B2, B3, C and D are presented in Table 2 (the sensory tests were conducted according to Chinese National Standard GB/T 14487-2008 (39)) and they indicate that enzymatic treatments had significant effects on the sensory quality.

The taste of sample CK was described as bitter and astringent with significant yin flavour, and its score was 83. In contrast, astringency decreased with the increase of laccase concentration, while bitterness decreased with the increase of $\alpha$-galactosidase concentration. The taste scores of A1, A2, A3, B1, B2 and B3 were 84, 86, 87, 87, 89 and 82, respectively; sample $C$ was mellow and slightly bitter, with score of 91; sample D was mellow, sweet and with significant yin flavour, with a taste score of 93 .

The aroma of sample CK was described as clean and pure and its score was 85 ; the aroma became stronger with the increase of $\alpha$-galactosidase concentration, but sample B3 was described as light; the aroma scores of A1, A2, A3, B1, B2 and B3 were 86, 88, 87, 89, 92 and 89, respectively; both samples $\mathrm{C}$ and $\mathrm{D}$ had intense and lasting aroma, and their scores were 91 and 93, respectively. In summary, these results indicate that the sensory quality of sample $\mathrm{D}$ was the best. Both laccase and $\alpha$-galactosidase showed significant effects on improving the sensory quality of Anxi summer tieguanyin tea. Laccase had a positive effect on the taste only, while $\alpha$-galactosidase had a positive effect mainly on the aroma and only partly affected the taste. Moreover, the experiments showed that the concentration of enzymatic solution was an important factor to influence the effects of exogenous enzymatic treatment on the sensory quality. When the mixed enzyme solution with $0.075 \mathrm{~g} / \mathrm{L}$ of laccase and $0.2 \mathrm{~g} / \mathrm{L}$ of $\alpha$-galactosidase was used, the tea received the highest score.

Table 2. Results of sensory evaluation of the summer tieguanyin tea from Anxi county after different enzymatic treatments

\begin{tabular}{|c|c|c|c|c|}
\hline \multirow{2}{*}{ Sample } & \multicolumn{2}{|l|}{ Flavour } & \multicolumn{2}{|l|}{ Aroma } \\
\hline & Sensory evaluation terms & Score & Sensory evaluation terms & Score \\
\hline CK & plain and thin, bitter and astringent, significant yin flavour & 83 & clean and pure & 85 \\
\hline A1 & not mellow enough, shows bitterness, slightly astringent, some yin flavour & 84 & pure and normal & 86 \\
\hline A2 & not mellow enough, shows bitterness, some yin flavour & 86 & clean aroma & 88 \\
\hline A3 & mellow and thick, slightly bitter, significant yin flavour & 87 & clean aroma, less pure & 87 \\
\hline B1 & not mellow and thick enough, slightly astringent, some yin flavour & 87 & clean aroma, not lasting enough & 89 \\
\hline B2 & mellow and thick, slightly astringent, significant yin flavour & 89 & intense aroma & 92 \\
\hline B3 & mellow, plain and thin, slightly sweet, some yin flavour & 82 & light & 89 \\
\hline $\mathrm{C}$ & heavy and mellow, slightly bitter, some yin flavour & 91 & intense and lasting aroma & 91 \\
\hline $\mathrm{D}$ & sweet, mellow and fresh, significant yin flavour & 93 & intense and lasting aroma & 93 \\
\hline
\end{tabular}

For sample abbreviations see legend of Fig. 1 


\section{Effects of enzymatic treatment on the taste of tieguanyin tea}

As shown in Fig. 1, the contents of tea polyphenols in samples $\mathrm{A} 1, \mathrm{~A} 2$ and $\mathrm{A} 3$, which were treated with different concentrations of laccase, were $12.3,11.9$ and $11.5 \%$, lower than the sample CK $(13.4 \%)$, their catechin content was $7.93,7.29$ and $6.73 \%$ respectively, which was lower than that of the sample CK $(8.32 \%)$, while the contents of tea polyphenols and catechin significantly decreased along with the increase of laccase concentration. Therefore, laccase treatment can reduce the content of tea polyphenols and this effect is concentration-dependent.

Similar results can also be observed in the samples treated with $\alpha$-galactosidase, marked B1, B2 and B3. The content of tea polyphenols in sample CK was $13.4 \%$ and it slightly decreased to $12.8,12.8$ and $12.7 \%$ after a treatment with different concentrations of $\alpha$-galactosidase (Fig. 1). However, the catechin content in samples B1, B2 and B3 $(8.24,8.23$ and $8.16 \%$, respectively) was slightly lower compared with sample CK (8.32\%), but this was not statistically significant. These results demonstrated that the effects of $\alpha$-galactosidase treatment on the content of tea polyphenols and catechins were relatively weak.

When the combination of these two enzymes (samples $C$ and D) was used, the content of both tea polyphenols and catechins decreased significantly compared with sample CK. When the concentration of $\alpha$-galactosidase (sample C) was $0.1 \mathrm{~g} / \mathrm{L}$, the reduction rate was similar to that of the samples treated with laccase only. However, after $0.2 \mathrm{~g} / \mathrm{L}$ of $\alpha$-galactosidase (sample D) was sprayed together with laccase, lower content of tea polyphenols and catechins was determined, which indicated that although the effect of $\alpha$-galactosidase alone on the summer tea was weak, it was able to enhance the effects of laccase on the content of tea polyphenols and catechins when these two enzymes were applied together.

As shown in Fig. 1, the total soluble sugars of samples treated with laccase alone (samples $\mathrm{A} 1, \mathrm{~A} 2$ and $\mathrm{A} 3$ ), $\alpha$-galactosidase alone (samples B1, B2 and B3) or the combination of the two enzymes (samples $C$ and $D$ ) were significantly higher than in the CK sample $(6.5,6.9$ and $7.6 \%$

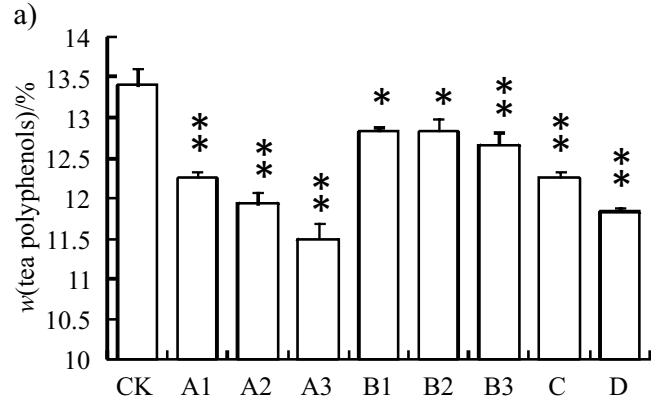

b)
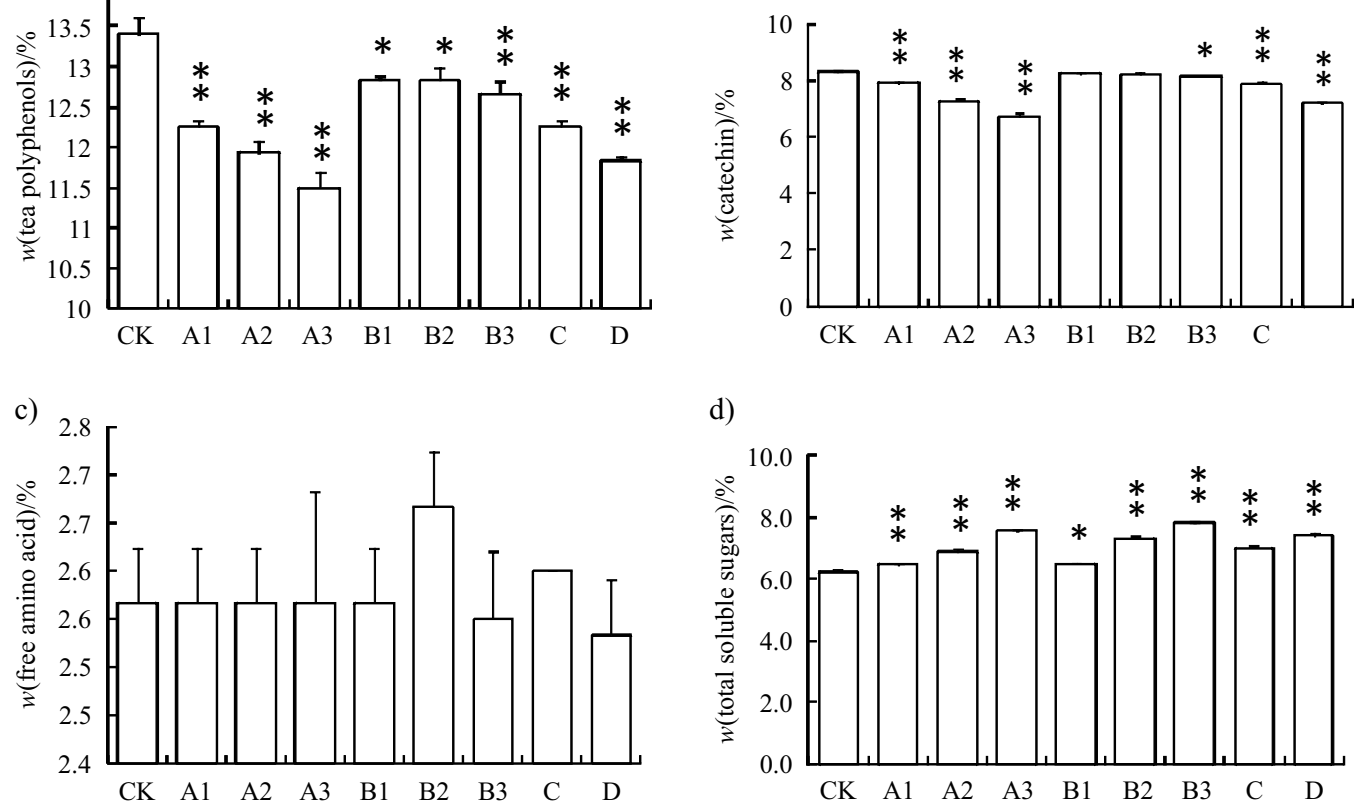

d)
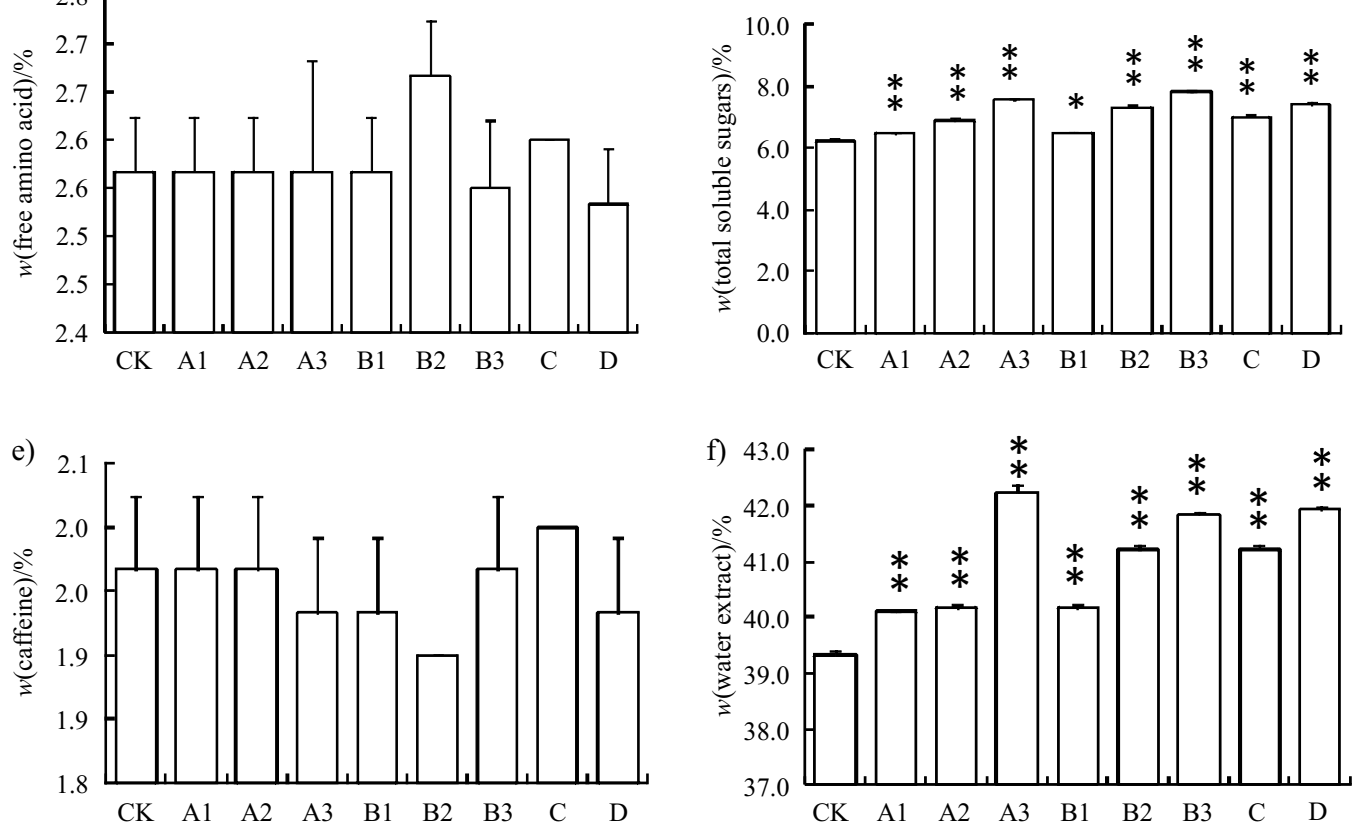

Fig. 1. Components in summer tieguanyin oolong tea treated with different enzyme concentrations (in g/L): not treated (CK), treated with laccase 0.05 (A1), treated with laccase 0.1 (A2), treated with laccase 0.2 (A3), treated with $\alpha$-galactosidase 0.1 (B1), treated with $\alpha$-galactosidase 0.2 (B2), treated with $\alpha$-galactosidase 0.4 (B3), treated with laccase 0.075 and $\alpha$-galactosidase 0.1 (C), treated with laccase 0.075 and $\alpha$-galactosidase $0.2(\mathrm{D})$.

*significant difference $(t$-test, $\mathrm{p}<0.05),{ }^{* *}$ very significant difference $(t$-test, $\mathrm{p}<0.01)$ 
in samples A1-A3, 6.5, 7.3 and $7.8 \%$ in samples B1-B3, 7.0 and $7.4 \%$ in samples $C$ and $D$, respectively, vs. $6.2 \%$ in sample CK). The same enhancement effects could be obtained for water extract content $(40.1,40.2$ and $42.2 \%$ in samples A1-A3, 40.2, 41.2 and $41.8 \%$ in samples B1-B3, 41.2 and $41.9 \%$ in samples $C$ and $D$, respectively, vs. 39.3 $\%$ in sample CK). The total soluble sugars and the content of water extract increased by 19.4 and $6.6 \%$ after the treatment with combined enzymes. The increased level of water extract in samples treated with laccase was higher than in the samples treated with $\alpha$-galactosidase, but the increased level of total soluble sugars in samples treated with laccase was lower than in samples treated with $\alpha$-galactosidase. Unlike these two results above, the content of caffeine and free amino acids was basically the same whether they were treated with laccase or $\alpha$-galactosidase.

It can be seen from the above results that the content of soluble polyphenols decreased after laccase treatment. After enzymatic treatment, the total soluble sugars and the content of water extract increased significantly, while the change of caffeine and free amino acids was not obvious. Decrease of catechins and polyphenols in tea could effectively reduce the bitterness and astringency of the summer tea; increase of the total soluble sugars and the content of the water extract could balance the flavour of tea infusion. The reason why $\alpha$-galactosidase treatment could result in an increase of total soluble sugars may be that $\alpha$-galactosidase can hydrolyse $\alpha$-glycosidic bond specifically, as has been previously reported in the literature. Both laccase and $\alpha$-galactosidase can destruct the cell wall structure and promote the release of intracellular nutrients, so the content of the water extract was significantly increased after enzymatic treatment.

Low quality of summer tea is difficult to improve only by adjusting the processing parameters; however, it has been reported that a treatment with exogenous enzymes can achieve the purpose by changing the contents of some constituents in the tea. The study found that the reason for the bitterness and astringency of Anxi summer tieguanyin tea is that the summer tea has lower soluble sugars and higher polyphenol content (40). Research has also shown that there are positive effects of the higher total soluble sugar ratio of tea polyphenols. The above results show that appropriate exogenous laccase and $\alpha$-galactosidase treatment could achieve the expected result of adjusting the content of polyphenols and total soluble sugars, which was proven by the sensory evaluation results.

\section{Effects of enzymatic treatment on the aroma of tieguanyin tea}

Fresh tea leaves are virtually odourless and the aroma components of tea are generated mainly because of biochemical and chemical reactions during tea processing. In our experiments, after the addition of exogenous enzymes, the aroma precursors were transformed into aroma components. Sixty-seven compounds were identified which can be divided into eight groups according to their structure: 6 aldehydes, 16 alcohols, 20 esters, 7 ketones, 1 acid, 5 alkenes, 3 alkanes and 9 other compounds.
Almost all the compounds have been identified as the aroma compounds of tea by Hara et al. (41). The main volatile constituents of the samples are shown in Table 3 and Fig. 2. The results illustrate that the relative content (values given as the ratio of the component peak area to the internal standard (ethyl decanoate) peak area) of the total essential oils in samples A1 (108.19), A2 (113.41), A3 (117.65), B1 (111.00), B2 (129.83), B3 (135.84), C (117.15) and D (123.26) was higher than that in sample CK (97.95). Compared to those in the control group, the total essential oils of tea sample D increased significantly, among which aldehydes increased by $23.28 \%$, alcohols by 37.05 $\%$, esters by $20.10 \%$ and alkenes by $38.99 \%$.

The main constituents of the essential oils were aldehydes, alcohols, esters and alkenes, which accounted for $70-80 \%$. Among them, the contents of aldehydes, alcohols, esters and alkenes in the samples treated with laccase and $\alpha$-galactosidase were obviously higher than in the CK sample. The samples treated with $\alpha$-galactosidase had a higher content of aldehydes and alcohols, but lower content of esters than those treated with laccase.

Nerolidol, indole and $\alpha$-farnesene were found to be the most important odour-active compounds in oolong tea (37). The smell of nerolidol is like the light fragrance of roses and apples, which is very sweet, refreshing and lasting. Indole can enhance the flavour of tea. The organoleptic character of farnesene is soft and mellow. Compared with sample $\mathrm{CK}$, all these three compounds were increased in sample D (53.34 vs. $38.09 \%$ of nerolidol, 11.52 vs. $10.33 \%$ of indole, and 12.90 vs. $9.21 \%$ of farnesene). Benzonitrile is considered as the unique constituent of tieguanyin (42), which was also detected in this study. Therefore, these odourants were the most important components of tieguanyin tea. The contents of these components in the samples treated with $\alpha$-galactosidase were much higher than in those treated with laccase and the sample CK. It is obvious that $\alpha$-galactosidase plays an important role in tea aroma formation.

Alcohols accounted for about half of the total essential oils. Linalool, phenylethyl alcohol, nerolidol and phytol were the main constituents of oolong tea. It is known that terpene alcohols, such as linalool can be generated by the hydrolysis of their glycosides, which are precursors of tea aroma, through the enzymatic action (43). Fig. 2 shows that the linalool, phenylethyl alcohol and nerolidol content greatly increased in the samples B2 and B3. Phenylethyl alcohol was considered as a tea aroma precursor (44), which increased in samples treated with enzymes. Nerolidol is the major component of volatile oil contributing to the odour of tieguanyin and is the most important indicator of the aroma of Fujian oolong tea (45). The content of phytol, the hydrolysed product of chlorophyll, was 8.51 $\%$ in sample A3, which was much higher than that in sample CK (6.01\%). In the above sensory evaluation, the colour of sample D was golden yellow, brighter than that of sample CK, and this change resulted from the effect of laccase.

Aldehydes accounted for above $10 \%$ of the total essential oils. (E)-2-hexenal, nonanal, palmitaldehyde and diallyl acetal belong to aliphatic aldehydes. (E)-2-hexenal is known to possess a strong green note. The relative level of (E)-2-hexenal is much higher in sample D (0.39) than in sample CK (0.25). Nonanal gives a pleasant rose note. 
Table 3. Aroma compounds and relative contents of tieguanyin tea samples from Anxi county after different enzymatic treatments

\begin{tabular}{|c|c|c|c|c|c|c|c|c|c|c|c|}
\hline \multirow{2}{*}{ No. } & \multirow{2}{*}{$\mathrm{RT} / \mathrm{min}$} & \multirow{2}{*}{ Compound } & \multicolumn{9}{|c|}{ Relative content* } \\
\hline & & & CK & A1 & A2 & A3 & B1 & B2 & B3 & $\mathrm{C}$ & $\mathrm{D}$ \\
\hline 1 & 5.691 & (E)-2-hexenal & 0.25 & 0.26 & 0.26 & 0.27 & 0.27 & 0.17 & 0.17 & 0.31 & 0.23 \\
\hline 2 & 5.825 & 3-hexen-1-ol & 0.09 & - & - & - & - & 0.08 & 0.10 & 0.11 & 0.06 \\
\hline 3 & 5.852 & butyl aldoxime, 3-methyl-, syn- & 0.24 & 0.30 & 0.34 & 0.33 & 0.29 & 0.14 & 0.15 & 0.30 & 0.15 \\
\hline 4 & 5.925 & butyl aldoxime, 2-methyl-, syn- & 0.16 & 0.15 & 0.14 & 0.14 & 0.16 & - & - & 0.21 & - \\
\hline 5 & 6.545 & butyl aldoxime, 3-methyl-, anti- & 0.11 & 0.12 & 0.13 & 0.15 & 0.14 & - & 0.11 & 0.16 & 0.11 \\
\hline 6 & 8.097 & isopropyl acetate & 0.25 & - & - & - & - & 0.33 & 0.35 & 0.27 & 0.24 \\
\hline 7 & 10.844 & benzaldehyde & 0.42 & 0.31 & 0.32 & 0.35 & 0.32 & 0.48 & 0.56 & 0.49 & 0.49 \\
\hline 8 & 17.217 & benzeneacetaldehyde & 9.45 & 10.12 & 10.52 & 11.31 & 10.56 & 13.92 & 15.31 & 11.46 & 11.80 \\
\hline 9 & 17.633 & (Z)-3,7-dimethyl-1,3,6-octatriene & 0.72 & 0.81 & 0.91 & 1.04 & 0.89 & 1.31 & 1.45 & 0.92 & 1.24 \\
\hline 10 & 21.223 & linalool & 0.53 & 0.46 & 0.52 & 0.49 & 0.57 & 0.92 & 0.98 & 0.61 & 0.73 \\
\hline 11 & 21.512 & nonanal & 0.19 & 0.21 & 0.21 & 0.22 & 0.22 & 0.35 & 0.41 & 0.24 & 0.33 \\
\hline 12 & 21.996 & phenylethyl alcohol & 2.36 & 2.98 & 3.09 & 3.16 & 3.26 & 3.34 & 3.58 & 3.42 & 2.41 \\
\hline 13 & 22.284 & neryl nitrile & 0.87 & 0.90 & 0.93 & 1.02 & 0.90 & 1.52 & 1.64 & 0.98 & 1.13 \\
\hline 14 & 22.985 & glycerin & 0.22 & - & - & - & - & - & - & - & - \\
\hline 15 & 23.599 & benzyl nitrile & 1.06 & 1.19 & 1.24 & 1.34 & 1.33 & 1.30 & 1.36 & 1.50 & 1.32 \\
\hline 16 & 25.693 & 4-tert-butyl-1-cyclohexene & 0.85 & 0.89 & 1.13 & 1.12 & 1.21 & 1.24 & 1.26 & 0.99 & 1.01 \\
\hline 17 & 29.842 & isopentyl hexanoate & - & - & - & - & 0.02 & - & - & - & - \\
\hline 18 & 30.086 & 3-phenylpropanol & - & 0.32 & 0.45 & - & 0.46 & - & 0.48 & - & - \\
\hline 19 & 30.838 & cholestan-22(26)-epoxy-3,16-dione & 0.09 & - & - & - & - & - & - & - & - \\
\hline 20 & 31.124 & benzyl isocyanide & - & 0.21 & 0.24 & 0.24 & 0.29 & - & - & - & - \\
\hline 21 & 32.093 & indole & 10.33 & 11.36 & 11.95 & 12.45 & 12.36 & 14.78 & 15.01 & 12.63 & 11.52 \\
\hline 22 & 32.249 & 2-phenylnitroethane & 1.57 & 1.62 & 1.75 & 1.83 & 1.83 & 1.78 & 1.80 & 2.04 & 1.41 \\
\hline 23 & 36.088 & (Z)-3-hexenyl hexanoate & 0.93 & 1.42 & 1.43 & 1.35 & 1.40 & 0.89 & 0.72 & 1.50 & 0.83 \\
\hline 24 & 36.310 & hexanoic acid, hexyl ester & 0.45 & 0.85 & 0.93 & 0.87 & 0.92 & 0.43 & 0.39 & 0.98 & 0.48 \\
\hline 25 & 36.470 & (E)-hexanoic acid, 2-hexenyl ester & 0.18 & 0.32 & 0.31 & 0.29 & 0.31 & 0.15 & 0.14 & 0.33 & 0.17 \\
\hline 26 & 36.671 & phenethyl isobutyrate & 0.35 & 0.44 & 0.43 & 0.44 & 0.45 & 0.22 & 0.21 & 0.54 & 0.24 \\
\hline 27 & 36.850 & cis-jasmone & 0.16 & 0.15 & 0.16 & 0.15 & 0.16 & 0.31 & 0.35 & 0.19 & 0.20 \\
\hline 28 & 38.663 & $\beta$-phenylethyl butyrate & 0.44 & 0.56 & 0.61 & 0.58 & 0.60 & 0.38 & 0.33 & 0.67 & 0.41 \\
\hline 29 & 40.613 & phenethyl-2-methyl butyrate & 1.81 & 2.13 & 2.19 & 2.19 & 2.13 & 1.55 & 1.44 & 2.35 & 1.69 \\
\hline 30 & 40.874 & $\delta$-nonalactone & 1.45 & 1.52 & 1.64 & 1.78 & 1.74 & 3.93 & 4.16 & 1.78 & 2.25 \\
\hline 31 & 40.958 & farnesol & 0.56 & 0.32 & 0.33 & 0.39 & 0.29 & - & 0.30 & 0.63 & 0.63 \\
\hline 32 & 41.527 & farnesene & 9.21 & 11.88 & 12.13 & 12.76 & 11.27 & 9.92 & 9.28 & 10.80 & 12.90 \\
\hline 33 & 42.179 & 2-allyl-1,3-cyclohexanedione & 0.15 & 0.14 & 0.15 & 0.15 & 0.13 & 0.16 & 0.16 & 0.14 & 0.14 \\
\hline 34 & 43.550 & $p$-menth-4-en-3-one & - & - & - & - & - & 0.14 & - & - & - \\
\hline 35 & 43.838 & nerolidol & 38.09 & 40.32 & 41.56 & 43.23 & 40.14 & 54.84 & 58.92 & 43.52 & 53.34 \\
\hline 36 & 44.024 & 3-hexen-1-ol benzoate & 0.21 & 0.26 & 0.24 & 0.24 & 0.23 & 0.22 & 0.19 & 0.27 & 0.24 \\
\hline 37 & 44.163 & 7,8-dihydrolinalool & - & - & - & - & - & 0.14 & 0.10 & - & 0.09 \\
\hline 38 & 44.293 & 6,11-dimethyl-2,6,10-dodecatrien-1-ol & 0.21 & 0.32 & 0.34 & 0.34 & 0.32 & 0.23 & 0.22 & 0.31 & 0.34 \\
\hline 39 & 47.152 & 2-phenylethyl hexanoate & 1.02 & 1.25 & 1.31 & 1.40 & 1.27 & 0.92 & 0.88 & 1.37 & 0.96 \\
\hline 40 & 47.510 & methyl jasmonate & - & 0.21 & 0.19 & - & 0.21 & 0.41 & 0.46 & - & - \\
\hline 41 & 53.803 & neophytadiene & 0.26 & 0.23 & 0.22 & 0.35 & 0.23 & 0.21 & 0.19 & 0.29 & 0.23 \\
\hline 42 & 53.925 & hexahydrofarnesyl acetone & 0.19 & 0.18 & 0.18 & 0.20 & 0.18 & 0.15 & 0.13 & 0.21 & 0.14 \\
\hline 43 & 53.992 & octanoic acid, 2-phenylethyl ester & 0.06 & 0.06 & 0.06 & 0.07 & 0.07 & - & - & 0.07 & - \\
\hline 44 & 54.162 & hydroxyethyl palmitamide & 0.25 & 0.26 & 0.27 & 0.31 & 0.27 & 0.16 & 0.16 & 0.30 & 0.17 \\
\hline 45 & 54.379 & isobutyl phthalate & 0.07 & 0.09 & 0.13 & 0.08 & 0.14 & 0.10 & 0.09 & 0.08 & 0.05 \\
\hline 46 & 54.562 & trans-phytol & 0.10 & 0.05 & 0.07 & 0.12 & 0.08 & 0.10 & 0.13 & 0.13 & 0.10 \\
\hline 47 & 54.954 & methyl palmitoleate & - & 0.05 & 0.05 & 0.05 & 0.05 & 0.05 & 0.05 & 0.05 & 0.06 \\
\hline 48 & 55.118 & 2-pentadecanone, 6,10,14-trimethyl- & 0.10 & - & - & - & - & 0.18 & 0.20 & 0.14 & 0.15 \\
\hline
\end{tabular}


Table 3. - continued

\begin{tabular}{|c|c|c|c|c|c|c|c|c|c|c|c|}
\hline \multirow{2}{*}{ No. } & \multirow{2}{*}{$\mathrm{RT} / \mathrm{min}$} & \multirow{2}{*}{ Compound } & \multicolumn{9}{|c|}{ Relative content ${ }^{*}$} \\
\hline & & & CK & A1 & A2 & $\mathrm{A} 3$ & B1 & B2 & B3 & $\mathrm{C}$ & $\mathrm{D}$ \\
\hline 49 & 55.175 & farnesylacetone & 0.09 & 0.04 & 0.04 & 0.05 & - & 0.12 & 0.11 & 0.11 & 0.12 \\
\hline 50 & 55.281 & methyl palmitate & 0.13 & 0.16 & 0.18 & 0.17 & 0.17 & 0.19 & 0.20 & 0.20 & 0.25 \\
\hline 51 & 55.596 & isophytol & 0.31 & 0.25 & 0.19 & 0.28 & 0.20 & 0.29 & 0.36 & 0.36 & 0.30 \\
\hline 52 & 55.844 & palmitic acid & 0.52 & 0.46 & 0.41 & 0.33 & 0.33 & 1.20 & 1.30 & 0.58 & 0.71 \\
\hline 53 & 56.709 & geranyl linalool isomer B & 0.11 & 0.12 & 0.16 & 0.15 & 0.13 & 0.15 & 0.15 & 0.13 & 0.21 \\
\hline 54 & 57.408 & phytol isomer & 0.06 & 0.04 & 0.04 & 0.06 & 0.04 & - & - & - & 0.05 \\
\hline 55 & 57.458 & methyl linoleate & 0.84 & 1.08 & 1.36 & 1.47 & 1.26 & 0.88 & 0.78 & 1.24 & 1.34 \\
\hline 56 & 57.541 & methyl linolenate & 1.83 & 2.36 & 2.89 & 3.19 & 2.75 & 2.22 & 2.03 & 2.74 & 2.98 \\
\hline 57 & 57.625 & trans-piperitol & 0.08 & - & - & - & - & 0.03 & 0.03 & 0.05 & - \\
\hline 58 & 57.681 & phytol & 6.01 & 6.98 & 7.57 & 8.51 & 6.94 & 4.56 & 4.13 & 6.05 & 4.92 \\
\hline 59 & 57.999 & palmitaldehyde, diallyl acetal & 0.48 & 0.10 & 0.10 & 0.12 & 0.10 & 0.35 & 0.46 & 0.55 & 0.46 \\
\hline 60 & 58.181 & ethyl linoleate & 0.08 & 0.09 & 0.09 & 0.09 & 0.09 & - & - & 0.10 & - \\
\hline 61 & 58.259 & ethyl linoleolate & 0.10 & 0.20 & 0.22 & 0.21 & 0.20 & 0.10 & 0.09 & 0.22 & 0.06 \\
\hline 62 & 58.417 & dodecanamide & - & - & - & - & - & 0.20 & - & - & - \\
\hline 63 & 58.649 & octadecane & 0.09 & - & - & - & - & 0.17 & 0.20 & 0.17 & 0.16 \\
\hline 64 & 58.777 & cis-9-hexadecenal & 0.12 & 0.06 & 0.06 & 0.06 & 0.08 & 0.23 & 0.28 & 0.14 & 0.14 \\
\hline 65 & 59.458 & squalene & 0.81 & 0.82 & 0.82 & 0.81 & 0.83 & 1.17 & 1.23 & 0.94 & 1.09 \\
\hline 66 & 59.583 & hexahydronerolidol & 0.06 & - & - & - & - & 0.09 & 0.09 & 0.06 & 0.07 \\
\hline \multirow[t]{3}{*}{67} & 61.908 & heneicosane & 0.22 & 0.21 & 0.22 & 0.16 & 0.21 & 0.27 & 0.28 & 0.22 & 0.25 \\
\hline & & Total essential oils & 97.95 & 108.19 & 113.41 & 117.65 & 111.00 & 129.83 & 135.84 & 117.15 & 123.26 \\
\hline & & Total aroma compounds & 59 & 55 & 55 & 52 & 55 & 56 & 57 & 57 & 55 \\
\hline
\end{tabular}

*Values are given as the ratio of the component peak area to the internal standard (ethyl decanoate) peak area; RT=retention time of each peak; -=not detected

For sample abbreviations see legend of Fig. 1

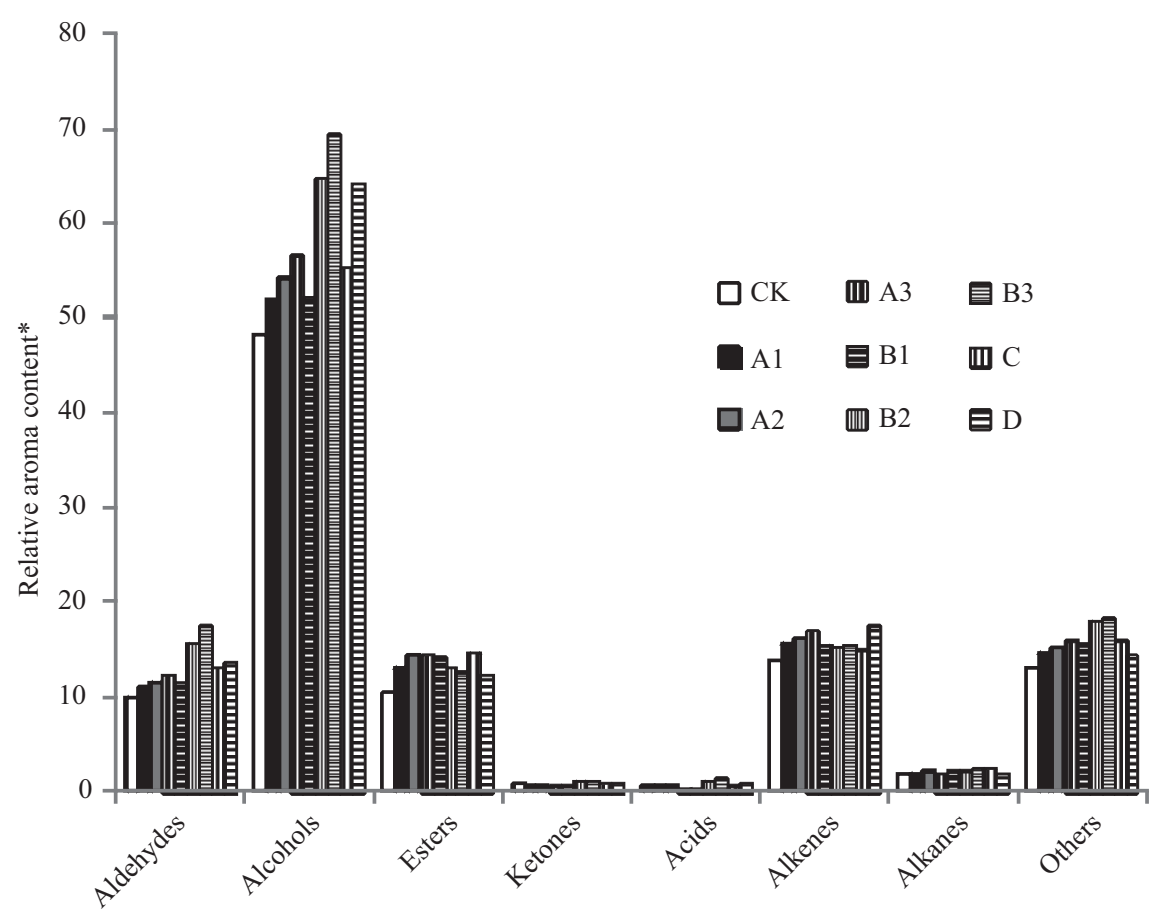

Fig. 2. Comparison of aroma profiles of samples of tieguanyin tea from Anxi county treated with different enzyme concentrations (for sample abbreviations see legend of Fig. 1)

*Values are given as the ratio of the component peak area to the internal standard (ethyl decanoate) peak area 
Benzeneacetaldehyde has a characteristic hyacinth-like odour. The contents of nonanal, benzaldehyde and benzeneacetaldehyde in sample D were much higher than in sample CK.

Esters, the main constituents of the essential oils, always have a characteristic pleasant flowery aroma. There were 20 kinds of esters detected in the tea samples. In green tea, oolong tea and black tea, $(Z)$-3-hexenyl hexanoate has been reported as one of the most important aroma compounds exhibiting a green note, although its concentration was not fairly high $(46-48)$. The relative level of (Z)-3-hexenyl hexanoate was much higher in the samples treated with laccase than in sample CK. The contents of methyl palmitate, methyl linoleate and methyl linolenate in samples treated with $\alpha$-galactosidase and laccase were much higher than in sample CK. These components showed lasting aroma (49). Farnesene is the most abundant alkene in tieguanyin oolong tea. It largely increased in samples treated with $\alpha$-galactosidase or laccase. However, the exception was observed in sample D, in which the content of alkanes decreased.

Research shows that the better quality tea has a higher content of total essential oils and higher boiling point of aroma components (50). Therefore, these parameters can be used as a quality standard for tieguanyin tea from Anxi county. In this experiment, the total essential oil content of samples treated with laccase and $\alpha$-galactosidase was significantly higher than in sample CK. The content of the characteristic aroma components with high boiling point, such as nerolidol, $\alpha$-farnesene, phenylethyl alcohol, benzeneacetaldehyde, (Z)-3-hexenyl hexanoate, and methyl palmitate showed the same trend. This indicates that the appropriate exogenous enzyme treatment can improve the aroma of summer tieguanyin tea from Anxi county, which was confirmed by the results of sensory evaluation.

\section{Conclusions}

In conclusion, laccase and $\alpha$-galactosidase significantly improved the sensory quality of tieguanyin tea from Anxi county, China, harvested in summer, which has been confirmed by sensory evaluation by the tea tasting experts and the results of main flavour substance analysis. Laccase had positive effect on the taste and $\alpha$-galactosidase on the aroma. Spraying the tea leaves with the solution of the two enzymes could improve the tea quality, but the aroma of the tea remained similar to that treated with $\alpha$-galactosidase alone. Treatment of tea with laccase and $\alpha$-galactosidase has been rarely reported. Our study demonstrated that this treatment could improve the sensory quality of summer tieguanyin tea from Anxi county effectively. The results also show that the exogenous enzymatic treatment method can be potentially applied in other tea production processes, widening the application range of laccase and $\alpha$-galactosidase.

\section{Acknowledgements}

The authors are very grateful for the financial support from the project of Fujian Provincial Bureau of Quality and Technical Supervision (No. FJQ12009006); Anhui
Scientific and Technological Project 1406C085017; National Commonwealth Research of General Administration of Quality Supervision, Inspection and Quarantine of the People's Republic of China (201210075); and the Doctoral Program of Higher Education Research Fund (Doctoral category 20113418110001).

\section{References}

1. Wan XC, Li DX, Zhang ZZ. Green tea and black tea manufacturing and consumption. In: Ho CT, Lin JK, Shahidi F, editors. Tea and tea products - chemistry and health-promoting properties. Boca Raton, FL, USA: CRC Press, Taylor \& Francis Group; 2008. pp. 1-8.

2. Sae-Tan S, Grove KA, Lambert JD. Weight control and prevention of metabolic syndrome by green tea. Pharmacol Res. 2011;64:146-54

http://dx.doi.org/10.1016/j.phrs.2010.12.013

3. Villaño D, Lettieri-Barbato D, Guadagni F, Schmid M. Effect of acute consumption of oolong tea on antioxidant parameters in healthy individuals. Food Chem. 2012;132:2102-06. http://dx.doi.org/10.1016/j.foodchem.2011.12.064

4. Li YY, Jiang CJ, Wan XC, Zhang ZZ, Li DX. Purification and partial characterization of $\beta$-glucosidase from fresh leaves of tea plants (Camellia sinensis (L.) O. Kuntze). Acta Biochim Biophy Sin. 2005;37:363-70.

http://dx.doi.org/10.1111/j.1745-7270.2005.00053.x

5. Cai JF, Guo YL. Effect of green-making practice using airconditioner on oolong tea quality. Fujian Tea. 2000;3:10-12,53 (in Chinese).

6. Zhang WJ, Liang YR, Zhang YG, Chen CS, Zhang FZ. Effects of shading on quality and chemical components of oolong tea in summer. Fujian J Agricul Sci 2006;21:360-5 (in Chinese).

7. Lin JK, Chen QB, Wang XX, Xiao H, Lin JR, Tian YL. Effects of humidification, sunlight and withering on the quality of soft scent summer oolong tea. Chin Agric Sci Bull. 2011;27: 409-13 (in Chinese).

8. Murugesan GS, Angayarkanni J, Swaminathan K. Effect of tea fungal enzymes on the quality of black tea. Food Chem. 2002;79:411-7. http://dx.doi.org/10.1016/S0308-8146(02)00157-7

9. Kumar CS, Subramanian R, Jaganmohan Rao L. Application of enzymes in the production of RTD black tea beverages: a review. Crit Rev Food Sci Nutr. 2013;53:180-97. http://dx.doi.org/10.1080/10408398.2010.520098

10. Sun QF, Liang YR, Lu JL. Effects of $\beta$-glucosidase on aroma of green tea soup. J Tea. 2007;33:211-3 (in Chinese).

11. Feng Y, Su ZC. Effects of processing treatment of exogenous enzymes on the quality of summer green tea. Sci Technol Food Ind. 2007;28:107-9 (in Chinese).

12. $\mathrm{Xu} \mathrm{YQ,} \mathrm{Zhong} \mathrm{XY,} \mathrm{Chen} \mathrm{SQ,} \mathrm{Yin} \mathrm{JF.} \mathrm{Hydrolysis} \mathrm{of} \mathrm{green} \mathrm{tea}$ residue protein using proteolytic enzyme derived from Aspergillus oryzae. J Food Sci Technol. 2013;50:171-5. http://dx.doi.org/ 10.1007/s13197-011-0239-x

13. Li ZH, Liu TX. Effects of different enzymes on the quality of pu-erh tea. Sci Technol Food Ind. 2008;29:152-4 (in Chinese).

14. Lontie R, editor. Copper proteins and copper enzymes, Vol. III, Boca Raton, FL, USA: CRC Press, Taylor \& Francis Group; 1984. pp. 1-35.

15. Baldrian P. Fungal laccase - occurrence and properties. FEMS Microbiol Rev. 2006;30:215-42. http://dx.doi.org/10.1111/j.1574-4976.2005.00010.x

16. Claus H. Laccases and their occurrence in prokaryotes. Arch Microbiol. 2003;179:145-50. http://dx.doi.org/10.1007/s00203-002-0510-7 
17. Canfora L, Iamarino G, Rao MA, Gianfreda L. Oxidative transformation of natural and synthetic phenolic mixtures by Trametes versicolor laccase. J Agric Food Chem. 2008;56: 1398-407. http://dx.doi.org/10.1021/jf0728350

18. Luo YH, Zuo Y, Su YQ, Ma HL. Study of kinetic behavior of the biocatalysis of laccase in the oxidation of phenolic compounds - using catechol and epicatechin as model substrates. Chem Ind Forest Prod. 2008;28:13-7 (in Chinese).

19. Yue K. Study on the synthesizing theaflavins by using laccase enzyme-catalysing oxidation. Acad Period Farm Prod Proc. 2008;139:57-9 (in Chinese).

20. Minussi RC, Pastore Gláucia M, Durán N. Potential applications of laccase in the food industry. Trends Food Sci Technol. 2002;13:205-16. http://dx.doi.org/10.1016/S0924-2244(02)00155-3

21. D'Annibale A, Stazi SR, Vinciguerra V, Sermanni GG. Oxirane immobilized lintinula edodes laccase: stability and phenolics removal efficiency in olive mill wastewater. J Biotechnol. 2000;77:265-73.

http://dx.doi.org/ 10.1016/S0168-1656(99)00224-2

22. Osma JF, Toca-Herrera JL, Rodríguez-Couto S. Uses of laccases in the food industry. Enzyme Res. 2010;2010:8. http://dx.doi.org/ 10.4061/2010/918761

23. Kuo TM, Van Middlesworth JF, Wolf WJ. Content of raffinose oligosaccharides and sucrose in various plant seeds. J Agric Food Chem. 1998;36:32-6. http://dx.doi.org/ 10.1021/jf00079a008

24. Ghazi S, Rooke J, Galbraith H. Improvement of the nutfitive value of soybean meal by protease and $\alpha$-galactosidase treatment in broiler cocherels and broiler chicks. Brit Poult Sci. 2003;44:410-8. http://dx.doi.org/ 10.1080/00071660310001598283

25. Yang GD, Liu F, Li H. Advances in the research of $\alpha$-galactosidase. Mod Food Sci Technol. 2006;22:275-6,279 (in Chinese).

26. Mulimani VH, Devendra S. Effect of soaking-cooking and crude $\alpha$-galactosidase treatment on the oligosaccharide content of red gram flour. Food Chem. 1998;61:475-9. http://dx.doi.org/ 10.1016/S0308-8146(97)00142-8

27. Juana F, Rosa D, Concepcion V.V. Kinetics of soluble carbohydrates by action of endo/exo $\alpha$-galactosidase enzyme in lentils and peas. Eur Food Res Technol. 2003;216:199-203. http://dx.doi.org/ 10.1007/s00217-002-0638-3

28. Gote MM, Khan ML, Khire JM. Active site directed chemical modification of $\alpha$-galactosidase from Bacillus stearothermophilus (NCIM 5146): involvement of lysine, tryptophan and carboxylate residues in catalytic site. Enzyme Microb Technol. 2007;40:1312-20. http://dx.doi.org/ 10.1016/j.enzmictec.2006.10.004

29. Chinese National Standard GB/T 19598-2006. Product of geographical indication - Anxi tieguanyin tea. Beijing, China: Standardization Administration of the People's Republic of China; 2006 (in Chinese).

30. Chinese National Standard GB/T 23776-2009. Methodology of sensory evaluation of tea. Beijing, China: Standardization Administration of the People's Republic of China; 2009 (in Chinese).

31. ISO 14502-1:2005. Determination of substances characteristic of green and black tea - Part 1: Content of total polyphenols in tea - Colorimetric method using Folin-Ciocalteu reagent. Geneva, Switzerland: International Organization for Standardization; 2005.

32. Chinese National Standard GB/T 8312-2013. Determination of caffeine content in tea. Beijing, China: Standardization Administration of the People's Republic of China; 2013 (in Chinese)

33. ISO 14502-2:2005. Determination of substances characteristic of green and black tea - Part 2: Content of catechins in green tea - Method using high-performance liquid chromatography. Geneva, Switzerland: International Organization for Standardization; 2005.

34. Chinese National Standard GB/T 8305-2013. Determination of water extract in tea. Beijing, China: Standardization Administration of the People's Republic of China; 2013 (in Chinese).

35. Wang DF, Zhou XL, Li L, Hou YF, Sun JP, Wang JF. A rapid quantitative method for polysaccharides in green tea and oolong tea. Eur Food Res Technol. 2008;226:691-6. http://dx.doi.org/ 10.1007/s00217-007-0578-z

36. Chinese National Standard GB/T 8314-2013. Determination of free amino acids content in tea. Beijing, China: Standardization Administration of the People's Republic of China; 2013 (in Chinese).

37. Kawakami M. Ganguly SN, Banerjee J, Kobayashi A. Aroma composition of oolong tea and black tea by brewed extraction method and characterizing compounds of Darjeeling tea aroma. J Agric Food Chem. 1995;43:200-7. http://dx.doi.org/ 10.1021/jf00049a037

38. Mass Spectral Library, National Institute of Standards and Technology. Gaithersburg, MD, USA.

39. Chinese National Standard GB/T 14487-2008. Terms of tea sensory tests. Beijing, China: Standardization Administration of the People's Republic of China; 2008 (in Chinese).

40. Wan XC, editor. Tea biochemistry. Beijing, China: Chinese Agricultural Press; 2003

41. Hara Y, Luo SJ, Wickremashinghe RC, Yamanishi T. VIII. Flavour of tea. Food Rev Int. 1995;11:477-525. http://dx.doi.org/10.1080/87559129509541056

42. Li FF, Guo WF. Analysis and comparison of aroma compositions in Biluozhenzhu tea and TieGuanYin tea leaves. J Zhejiang University (Science Edition). 2009;36:557-60. http://dx.doi.org/10.3785/j.issn.1008-9497.2009.05.017

43. Sakata K, Watanabe N. Importance of glycosides as alcoholic aroma precursors in plants: molecular basis of alcoholic aroma formation in tea and flowers. J Appl Glycosci. 1998;45: 123-9. http://dx.doi.org/10.11541/jag1994.45.123

44. Sakata K. $\beta$-Primeverosidase relationship with floral tea aroma formation during processing of oolong tea and black tea. In: Parliment TH, Ho CT, Schieberle P, editors. Caffeinated beverages: health benefits, physiological effects and chemistry. Washington, DC, USA: American Chemical Society Press, ACS Symposium Series; 2000. pp. 327-35.

45. Zhong QS, Lu HP. Comparison of aroma constituents between oriental beauty tea and tieguanyin Tea Food Sci. 2009;30:182-6 (in Chinese).

46. Nose M, Nakatani Y, Yaminishi T. Studies on the flavour of green tea. Part IX. Identification and composition of intermediate and high boiling constituents in green tea flavor. Agric Biol Chem. 1971;35:261-71. http://dx.doi.org/10.1271/bbb1961.35.261

47. Renold W, Näf-Müller R, Keller U, Willhalm B, Günther O. An investigation of the tea aroma. Part I. New volatile black tea constituents. Helv Chim Acta. 1974;57:130-8. http://dx.doi.org/ 10.1002/hlca.19740570506

48. Ito Y, Sugimoto A, Kakuda T, Kubota K. Identification of potent odorants in chinese jasmine green tea scented with flowers of jasminum sambac. J Agric Food Chem. 2002;50: 4878-84. http://dx.doi.org/10.1021/jf020282h

49. Si HQ, Shen Q, Pang XL. Study on aroma characteristics and components of new-type scented tea. J Tea Sci. 2010;30:16772 (in Chinese).

50. Wu QE. Comparison of fragrance characteristics in Fujian oolong tea. J Fujian Agric College. 1989;18:62-6 (in Chinese). 